\title{
'I did not feel like a mother': The success and remaining challenges to exclusive formula feeding among HIV-positive women in Brazil
}

\author{
Sarah MacCarthy, ScD, MSc. ${ }^{1}$, Jennifer J.K. Rasanathan, MD, MPH. ${ }^{2}$, Amy Nunn, ScD, MS. \\ 1 , and Ines Dourado, PhD, MPH ${ }^{3}$ \\ ${ }^{1}$ Alpert Medical School of Brown University and The Miriam Hospital, 164 Summit Avenue, \\ Providence, RI 02906 USA \\ 2Department of Family and Social Medicine, Montefiore Medical Center, 111 East $210^{\text {th }}$ Street, \\ Bronx, New York 10467 USA \\ ${ }^{3}$ Institute of Collective Health, Rua Basilio da Gama, s/n - Campus Universitario Canela, Cep: \\ 40.110-040, Salvador - BA, Brazil
}

\begin{abstract}
Exclusive and safe formula feeding can eliminate the risk of vertical HIV transmission due to breastfeeding. Therefore many countries advise all HIV-positive women to avoid breastfeeding their infants. However, little research explores the experiences of women attempting to exclusively formula feed (EFF) in countries with free and universal access to HAART. This article examines the success of Brazil in supporting HIV-positive women as they EFF their infants. We conducted in-depth interviews with $30 \mathrm{HIV}$-positive women receiving care at the primary facility for HIV/AIDS in Salvador, Brazil about their attitudes and practices related to EFF as well as challenges with adhering to EFF. All interviews were recorded, professionally transcribed and translated, and then analyzed. Our results showed that one woman reported both breastfeeding and formula feeding her infant; all others reported EFF. Postpartum counseling regarding the risk of HIV transmission through breastfeeding was the primary motivation for EFF. Challenges included difficulty reconciling their perceptions that breastfeeding is an important maternal responsibility, trouble accepting that breastfeeding can cause potential to harm their infants, confronting HIVrelated stigma associated with EFF, and unexpected financial burdens due to EFF. We conclude that HIV-positive women adhered to national guidelines recommending EFF; this phenomenon has likely contributed to declining rates of vertical transmission in Brazil. Despite this success, many women experienced challenges with EFF. Greater support services may enhance Brazil's success in empowering HIV-positive women and eliminating vertical HIV transmission via breastfeeding.
\end{abstract}

CORRESPONDING AUTHOR: Sarah MacCarthy, sarah_maccarthy@brown.edu, tel: 011.703.447.3353, fax: 011.401.793.4534. INSTITUTIONAL REVIEW BOARD APPROVAL: The study was approved by an Ethics Committee at the State Secretary of Health in Salvador, Brazil and by the Harvard School of Public Health in Boston, USA 


\section{Keywords}

HIV/AIDS; exclusive breast feeding; exclusive formula feeding; Brazil

\section{INTRODUCTION}

Exclusive and safe formula feeding can eliminate the risk of vertical transmission due to breastfeeding (Iliff PJ et al., 2005), while access to antiretroviral prophylaxis when formula is unsafe or unavailable decreases the risk of transmission via breast milk to less than one percent. (Chasela CS et al., 2010; Jamieson DJ et al., 2012) In contrast, non-exclusive breastfeeding (mixed feeding) has been shown to more than double the risk of seroconversion (Coovadia HM et al., 2007; Iliff PJ, et al., 2005; Kuhn L et al., 2007) but continues to occur (Ladzani, Peltzer, Mlambo, \& Phaweni, 2011; Maman S et al., 2012; Maru et al., 2009; Shapiro RL et al., 2003) despite global guidelines recommending either exclusive formula feeding (EFF) or exclusive breastfeeding (EBF) with ARVs for the first six months of life where replacement feeding is unsafe. (World Health Organization, UNAIDS, UNFPA, \& UNICEF, 2010; World Health Organization, UNICEF, UNAIDS, \& UNFPA, 2003; World Health Organization, UNICEF, UNFPA, \& UNAIDS, 2006, 2007) These guidelines call for national health authorities to adopt country-specific HIV and infant feeding policies.

In Brazil, where antiretroviral medicines (ARVs) have been free and universally available since 1997, national HIV and infant feeding guidelines recommend avoiding breastfeeding by all HIV-positive mothers, regardless of their living conditions. (Ministerio da Saude, Secretaria de Vigilancia em Saude, \& Departamento de DST, 2010) Brazil's Health Ministry also provides free infant formula to all HIV-positive mothers. (Ministerio da Saude, et al., 2010) As the HIV epidemic was taking root and expanding in Brazil in the past 30 years, (Bastos \& Szwarcwald, 2000; Berkman, Garcia, Munoz-Laboy, Paiva, \& Parker, 2005; Szwarcwald, 2008) nation-wide campaigns to promote breastfeeding among all women have effectively increased breastfeeding rates and duration. (Cardoso, Vicente, Damiao, \& Rito, 2008) As such, Brazilian women living with HIV are advised and encouraged to adopt EFF in a social setting that strongly favors breastfeeding. Data from Brazil demonstrates that substantial progress has been made as a result of ARVs, coupled with polices to support EFF: 1019 cases of vertical transmission were reported in 1998 whereas 104 cases were reported in 2011. (Ministério da Saúde, Secretaria de Vigilância em Saúde, \& Departamento de DST, 2012)

Given the substantial reductions in vertical transmission with EFF, many countries advise all HIV-positive women to avoid breastfeeding their infants. (Iliff PJ, et al., 2005) However, little research has explored the experiences of women who attempt to EFF in countries with free and universal access to HAART. This article therefore examines the attitudes, practices and challenges of HIV-positive women who engage in EFF through in-depth qualitative interviews. 


\section{METHODS}

This qualitative study among $30 \mathrm{HIV}$-positive women was conducted in Salvador, the capital city of Bahia state and one of the poorest regions of Brazil. Issues related to EFF as highlighted in the peer-reviewed literature informed the semi-structured interview guide. Further, a team of local experts provided input to develop open-ended questions about attitudes, practices and challenges regarding breastfeeding. The interview script underwent extensive field-testing, and researchers met weekly to review the test interviews for clarity in questions asked and quality of information collected. Women were recruited for the study at the primary facility for HIV/AIDS care in the state of Bahia. All interviews were recorded and then professionally transcribed and translated from Portuguese into English. In addition, interviewers submitted field notes summarizing their impressions from the interview.

The following steps were taken to analyze translated interview transcripts: Transcripts and related field notes were reviewed; based on barriers highlighted in peer-reviewed literature, potential challenges were identified through deductive coding. Next, inductive coding was used to distinguish new factors that may not have been previously identified; all codes were discussed between two researchers and further refined. As challenges related to EFF were identified, data was pulled from relevant interviews to identify the scope of evidence available, and exemplars were identified to further illuminate the challenges highlighted from each interview. Finally, discrepant cases, those experiences that deviated from the majority of women in the sample, were also examined.(Bernard, 2006)

\section{RESULTS}

Demographic characteristics of all women included in the study are summarized in Table 1. With respect to infant feeding practices, the vast majority of women (97\%) reported EFF, and only one woman engaged in mixed feeding. Several women $(\mathrm{N}=14)$ cited the comprehensive post-partum HIV counseling they received as a primary factor influencing decisions to EFF, as it taught them about the risks of vertical transmission and helped them cope with the psychological shock many felt upon hearing they should not breastfeed.

Most women ( $\mathrm{N}=29)$ were able to successfully EFF; challenges women encountered in their efforts to EFF were not insurmountable in most cases. Nonetheless, more than half of women $(\mathrm{N}=18)$ reported barriers to EFF. Women's challenges in attempting to comply with EFF comprised four broad themes: difficulty reconciling their perceptions that breastfeeding is an important maternal responsibility, trouble accepting that breastfeeding can cause potential to harm their infants, confronting HIV-related stigma associated with EFF, and unexpected financial burdens due to EFF. Quotes from interviewees illustrating these themes are captured in Table 2.

\section{DISCUSSION}

Qualitative data from this study demonstrate that, overall, HIV-positive women in our sample are able to successfully EFF. Importantly, a growing literature has documented that mixed feeding increases the risk of infant morbidity and mortality, including HIV seroconversion.(Ladzani, et al., 2011; Maman S, et al., 2012; Maru, et al., 2009; Shapiro RL, 
et al., 2003) Our results reflect the success of current public health programming for infant feeding by HIV-positive women in Salvador, Brazil.

Although 97\% of women living with HIV were able to successfully EFF, participants identified four major challenges that they faced - and successfully overcame - in their efforts to EFF. Barriers limiting women's ability to EFF have been identified in other national contexts, (Maman S, et al., 2012; Oladokun, Brown, \& Osinusi, 2010; ÿstergaard LR \& A., 2010; Sibeko, Coutsoudis, Nzuza, \& Gray-Donald, 2009; Thairu, Pelto, Rollins, Bland, \& Ntshangase, 2005) including Brazil, (Hebling EM \& Hardy E, 2007) and are further corroborated by this study. As evidenced by these HIV-positive Brazilian women, comprehensive counseling enabled them to forgo breastfeeding despite identified personal, social and economic challenges to doing so. Studies in Nigeria, (Brown, Oladokun, \& Osinusi, 2009) South Africa, (Bland RM et al., 2007; Nor et al., 2009) Burkina Faso, Cambodia and Cameroon (Cames et al., 2010) have similarly identified the need for counseling to provide women with the skills to successfully formula feed.

Women's infant feeding practices experiences with counseling and persistent challenges to EFF described here reflect the components of infant feeding counseling currently provided to HIV-positive mothers and pregnant women. They also highlight the positive impact of counseling and the potential for pre- and post-partum HIV-positive women to maintain and further progress in the prevention of HIV transmission from mother-to-child. While most women successfully EFF, this study suggests that additional counseling services are needed to support pregnant or post-partum HIV-positive women as they encounter social norms and experience personal infant feeding desires that conflict with medical advice. Specifically, services should acknowledge and support women to overcome their emotional and psychological challenges. Counseling should seek to empower women with skills and strategies to navigate conflicting pressures, social norms, stigma and any negative interactions with their partners, families, physicians and communities. Further, discussions about transportation, childcare and other factors that may limit access to free infant formula are needed.

The main limitation of this study is that the qualitative data only captures women already in contact with the health system and may not have reached the most marginalized individuals. The qualitative interviews and the sample, therefore, cannot represent the whole of Salvador and may not generalizable to entire population of breastfeeding mothers. The amount of time between the completion of infant feeding and the interview varied among the sample and may also result in some recall bias. Additionally, data on infant HIV seroconversion were not collected, so results are not correlated with HIV transmission. Finally, women may have reported EFF in effort to give a socially desirable response. Still, this study expands the body of knowledge related to the challenges associated with EFF. In other middle and highincome countries that promote EFF, this level of success with dedicated infant feeding counseling could serve as a benchmark or model for context-specific replication. 


\section{CONCLUSION}

Brazil has achieved substantial success in the reduction of vertical transmission over the past 15 years. Women's successes with EFF documented here underscore the potential for health care providers to empower women to EFF, reduce persistent social and economic barriers to EFF and contribute to the elimination of vertical transmission via comprehensive medical and psychosocial counseling. Counseling services should extend beyond providing information on HIV transmission to include psychological support and coping strategies, while formula distribution services should consider the costs of EFF more broadly. Simultaneous, ongoing work to reduce HIV-related stigma may shift the social perception of HIV-positive mothers who avoid breastfeeding from being perceived as "bad mothers" to conscientious mothers acting in their infants' best interests. These efforts will maintain and enhance Brazil's success in empowering HIV-positive women and eliminating vertical HIV transmission via breastfeeding.

\section{Acknowledgments}

This publication resulted from research supported by the training grant entitled "HIV and Other Infectious Consequences of Substance Abuse (T32DA13911-12). In addition, this publication was made possible with help from the Lifespan/Tufts/Brown Center for AIDS Research (P30AI042853) from the National Institute Of Allergy And Infectious Diseases.

\section{WORKS CITED}

Bastos FI, Szwarcwald CL. AIDS and pauperization: principal concepts and empirical evidence. Cad Saude Publica. 2000; 16 Suppl 1(\#\#):65-76. [PubMed: 10904390]

Berkman A, Garcia J, Munoz-Laboy M, Paiva V, Parker R. A critical analysis of the Brazilian response to HIV/AIDS: lessons learned for controlling and mitigating the epidemic in developing countries. Am J Public Health. 2005; 95(7):1162-1172. [PubMed: 15933232]

Bernard, H. Research Methods in Anthropoligy: Qualitative and quantitative approaches. Fourth Edition. Vol. Vol.. UK: Altamira Press; 2006.

Bland RM, Becquet R, Rollins NC, Coutsoudis A, Coovadia HM, ML N. Breast health problems are rare in both HIV-infected and HIV-uninfected women who receive counseling and support for breast-feeding in South Africa. Clin Infect Dis. 2007; 45(11):1502-1510. [PubMed: 17990235]

Brown BJ, Oladokun RE, Osinusi K. Situation analysis of the existing infant feeding pattern at the commencement of the prevention of mother to child transmission (PMTCT) of HIV programme in Ibadan. Niger J Clin Pract. 2009; 12(4):421-428. [PubMed: 20329685]

Cames C, Saher A, Ayassou KA, Cournil A, Meda N, Simondon KB. Acceptability and feasibility of infant-feeding options: experiences of HIV-infected mothers in the World Health Organization Kesho Bora mother-to-child transmission prevention (PMTCT) trial in Burkina Faso. Matern Child Nutr. 2010; 6(3):253-265. [PubMed: 20929497]

Cardoso LO, Vicente AS, Damiao JJ, Rito RV. The impact of implementation of the Breastfeeding Friendly Primary Care Initiative on the prevalence rates of breastfeeding and causes of consultations at a basic healthcare center. J Pediatr (Rio J). 2008; 84(2):147-153. [PubMed: 18372932]

Chasela CS, Hudgens MG, Jamieson DJ, Kayira D, Hosseinipour MC, Kourtis AP, C Z. Maternal or infant antiretroviral drugs to reduce HIV-1 transmission. Engl J Med. 2010; 362(24):2271-2281.

Chisenga M, Siame J, Baisley K, Kasonka L, Filteau S. Determinants of infant feeding choices by Zambian mothers: a mixed quantitative and qualitative study. Matern Child Nutr. 2011; 7(2):148159. [PubMed: 21410882]

Coovadia HM, Rollins NC, Bland RM, Little K, Coutsoudis A, Bennish ML, Newell ML. Mother-tochild transmission of HIV-1 infection during exclusive breastfeeding in the first 6 months of life: an intervention cohort study. Lancet. 2007; 369(9567):1107-1116. [PubMed: 17398310] 
Desclaux A, Alfieri C. Counseling and choosing between infant-feeding options: overall limits and local interpretations by health care providers and women living with HIV in resource-poor countries (Burkina Faso, Cambodia, Cameroon). Soc Sci Med. 2009; 69(6):821-829. [PubMed: 19559512]

Doherty T, Chopra M, Nkonki L, Jackson D, Greiner T. Effect of the HIV epidemic on infant feeding in South Africa: "When they see me coming with the tins they laugh at me". Bull World Health Organ. 2006; 84(2):90-96. [PubMed: 16501725]

Hebling EM, Hardy E. Feelings related to motherhood among women living with HIV in Brazil: a qualitative study. AIDS Care. 2007; 19(9):1095-1100. [PubMed: 18058393]

Iliff PJ, Piwoz EG, Tavengwa NV, Zunguza CD, Marinda ET, Nathoo KJ, Z s. Early exclusive breastfeeding reduces the risk of postnatal HIV-1 transmission and increases HIV-free survival. AIDS. 2005; 19(7):699-708. group. [PubMed: 15821396]

Jamieson DJ, Chasela CS, Hudgens MG, King CC, Kourtis AP, Kayira D, C Z. Maternal and infant antiretroviral regimens to prevent postnatal HIV-1 transmission: 48-week follow-up of the BAN randomised controlled trial. Lancet. 2012; 379(9835):2449-2458. Epub 2012 Apr 2426. [PubMed: 22541418]

Kuhn L, Sinkala M, Kankasa C, Semrau K, Kasonde P, Scott N, Thea DM. High uptake of exclusive breastfeeding and reduced early post-natal HIV transmission. PLoS One. 2007; 26(2):12.

Ladzani R, Peltzer K, Mlambo MG, Phaweni K. Infant-feeding practices and associated factors of HIV-positive mothers at Gert Sibande, South Africa. Acta Paediatrica. 2011; 100(4):538-542. [PubMed: 21062356]

Maman S, Cathcart R, Burkhardt G, Omba S, Thompson D, Behets F. The infant feeding choices and experiences of women living with HIV in Kinshasa, Democratic Republic of Congo. [Research Support, U.S. Gov't, P.H.S.]. AIDS Care. 2012; 24(2):259-265. Epub 2011 Jul 2025. [PubMed: 21780955]

Maru S, Datong P, Selleng D, Mang E, Inyang B, Ajene A, Abimiku A. Social determinants of mixed feeding behavior among HIV-infected mothers in Jos Nigeria. AIDS Care. 2009; 21(9):11141123. [PubMed: 20024770]

Ministerio da Saude, Secretaria de Vigilancia em Saude, \& Departamento de DST, A., e Hepatites Virais. Recomendacoes para profilaxia da transmissao vertical do HIV e terapia antirretroviral em gestantes: guia de tratamento. Brasilia: 2010. p. 122

Ministério da Saúde, Secretaria de Vigilância em Saúde, \& Departamento de DST, A. e. H. V.. Boletim AIDS. Brasilia: 2012. Boletim Epidemiologico - Aids e DST.

Nor B, Zembe Y, Daniels K, Doherty T, Jackson D, Ahlberg BM, Ekstrom EC. "Peer but not peer": considering the context of infant feeding peer counseling in a high HIV prevalence area. J Hum Lact. 2009; 25(4):427-434. [PubMed: 19622755]

Oladokun RE, Brown BJ, Osinusi K. Infant-feeding pattern of HIV-positive women in a prevention of mother-to-child transmission (PMTCT) programme. AIDS Care. 2010; 22(9):1108-1114. [PubMed: 20229369]

Østergaard LR, A B. "They call our children "Nevirapine babies?" ": A qualitative study about exclusive breastfeeding among HIV positive mothers in Malawi. Afr J Reprod Health. 2010; 14(3):213-222. [PubMed: 21495616]

Shapiro RL, Lockman S, Thior I, Stocking L, Kebaabetswe P, Wester C, SJ H. Low adherence to recommended infant feeding strategies among HIV-infected women: results from the pilot phase of a randomized trial to prevent mother-to-child transmission in Botswana. AIDS Education and Prevention. 2003; 15(3):221-230. [PubMed: 12866834]

Sibeko L, Coutsoudis A, Nzuza S, Gray-Donald K. Mothers' infant feeding experiences: constraints and supports for optimal feeding in an HIV-impacted urban community in South Africa. Public Health Nutr. 2009; 12(11):1983-1990. [PubMed: 19323863]

Szwarcwald CL. Strategies for improving the monitoring of vital events in Brazil. International Journal of Epidemiology. 2008; 37(4):738-744. [PubMed: 18653509]

Thairu LN, Pelto GH, Rollins NC, Bland RM, Ntshangase N. Sociocultural influences on infant feeding decisions among HIV-infected women in rural Kwa-Zulu Natal, South Africa. Matern Child Nutr. 2005; 1(1):2-10. [PubMed: 16881874] 
World Health Organization, UNAIDS, UNFPA, \& UNICEF. Guidelines on HIV and infant feeding 2010: Principles and recommendations for infant feeding in the context of HIV and a summary of evidence. 2010; Vol. 2011

World Health Organization, UNICEF, UNAIDS, \& UNFPA. HIV and infant feeding: a guide for health care managers and supervisors. Geneva: 2003.

World Health Organization, UNICEF, UNFPA, \& UNAIDS. Report of a Technical consultation held on behalf of the Inter-agency Task Team (IATT) on Prevention of HIV Infections in Pregnant Women, Mothers and their Infants. Vol. Vol. 2011. Geneva: 2006. HIV and infant feeding: new evidence and programmatic experience.

World Health Organization, UNICEF, UNFPA, \& UNAIDS. [Retrieved July 20, 2011] HIV and infant feeding update. 2007. from http://www.who.int/child_adolescent_health/documents/ 9789241595964/en/index.html 


\section{Table 1}

Demographic characteristics of women in the sample $(n=30)$

\begin{tabular}{|c|c|c|}
\hline VARIABLES & $\mathbf{n}$ & percentage \\
\hline \multicolumn{3}{|l|}{ Civil status } \\
\hline Married or live with someone & 19 & $63 \%$ \\
\hline Single, divorced, or widowed & 11 & $37 \%$ \\
\hline \multicolumn{3}{|l|}{$A g e^{*}$} \\
\hline $20-25$ years & 6 & $20 \%$ \\
\hline $26-31$ years & 15 & $50 \%$ \\
\hline $32-37$ years & 6 & $20 \%$ \\
\hline 38 years or older & 3 & $10 \%$ \\
\hline \multicolumn{3}{|l|}{ Race / ethnicity ${ }^{* *}$} \\
\hline White & 1 & $3 \%$ \\
\hline Brown & 11 & $37 \%$ \\
\hline Black & 13 & $43 \%$ \\
\hline Other & 5 & $17 \%$ \\
\hline \multicolumn{3}{|l|}{ Residence } \\
\hline Outside of metropolitan Salvador & 10 & $33 \%$ \\
\hline Salvador & 20 & $66 \%$ \\
\hline \multicolumn{3}{|l|}{ Employment status } \\
\hline Unemployed & 21 & $70 \%$ \\
\hline Employed (formally or informally) & 9 & $30 \%$ \\
\hline \multicolumn{3}{|l|}{ Monthly income } \\
\hline Minimum wage or below & 6 & $67 \%$ \\
\hline Above minimum wage & 3 & $33 \%$ \\
\hline
\end{tabular}

* The women reported their age at the time of the interview, which was not necessarily their age at the time of breastfeeding.

Race and ethnicity in Brazil is complex and is commonly referred to as 'color' to reference the phenotype (physical appearance) and not one's ancestry (origin). 


\section{Table 2}

Quotes illustrating key themes highlighted in the qualitative interviews $(n=30)$

\begin{tabular}{|c|c|}
\hline THEMES & Quote illustrating the key theme \\
\hline $\begin{array}{l}\text { Reported no challenges } \\
\text { associated with EFF and } \\
\text { highlighted the role of } \\
\text { comprehensive counseling from } \\
\text { the health care worker. }\end{array}$ & $\begin{array}{l}\text { Interviewer: What about the news that you cannot breastfeed? How was that for you? Woman: Ah, that } \\
\text { part I did not like. Interviewer: Why? Woman: Because I wanted to breastfeed. I wanted to know what the } \\
\text { feeling [of breastfeeding] is like... But after I talked to the social worker, and she explained it all to me, I } \\
\text { don't feel like that anymore. }\end{array}$ \\
\hline $\begin{array}{l}\text { Difficulty reconciling their } \\
\text { perceptions that breastfeeding is } \\
\text { an important maternal } \\
\text { responsibility }(n=8)\end{array}$ & $\begin{array}{l}\text { Woman: I did not feel like a mother... At first, I didn't breastfeed, I didn't feel that [my baby] was mine } \\
\text { because I had not breastfed. }\end{array}$ \\
\hline $\begin{array}{l}\text { Trouble accepting that } \\
\text { breastfeeding can cause potential } \\
\text { to harm their infants }(n=6)\end{array}$ & $\begin{array}{l}\text { Woman: "Because... it is a bond between mother and son [that], unfortunately, you do not have. You } \\
\text { can't have! Because you want to protect your baby anyway. You know that with a gesture of affection you } \\
\text { can transmit a virus! A disease to your children! I get kind of sad that I couldn't care [for my] child in } \\
\text { that way!" }\end{array}$ \\
\hline $\begin{array}{l}\text { Confronting HIV-related stigma } \\
\text { associated with EFF }(\mathrm{n}=8)\end{array}$ & $\begin{array}{l}\text { Interviewer: "What about breastfeeding, talk a little bit about when you heard the news." Woman: "Oh! } \\
\text { A knife, right? It's hard! When I'm in the hospital, half of the people [are] breastfeeding and I will not be } \\
\text { able to breastfeed my child. Will someone ask, "Why aren't you breastfeeding?" So? It is embarrassing! It } \\
\text { [is] a big concern! I do not know... if [I will] be in a group or in a specific room only for those with HIV." }\end{array}$ \\
\hline $\begin{array}{l}\text { Unexpected financial burdens } \\
\text { due to } \mathrm{EFF}(\mathrm{n}=4)\end{array}$ & $\begin{array}{l}\text { Interviewer: "So, how was it for you at the time the doctor told you? Either in the maternity [ward] or } \\
\text { here...How was that for you? Woman: It was bad, right? I soon started thinking "My God, I'm } \\
\text { unemployed, no husband... how [am I] going to feed this boy?" }\end{array}$ \\
\hline
\end{tabular}

